\title{
Live Music and Consumers' Attitudes: An Abstract
}

\author{
Bruno Morgado Ferreira and Diana Marli
}

\begin{abstract}
Music, as marketing strategy, has played a key role for several companies. Related to this situation and given the constant evolution of preferences by increasingly demanding consumers, we intend to study the relationship between ambient music and live music on consumer behaviors. More specifically, our study aims to understand the influence of live music consumer behavior in relation to ambient music, as well as the aspects that consumers consider to be most relevant to their use in night spaces. In a field experiment, in a bar in Viseu (Portugal), a quantitative survey was conducted through a questionnaire survey, and a nonrandom sample was obtained. The research was conducted in two phases: the first with ambient music and the second with live music, in which the playlist of songs was the same. We obtained a total of 99 respondents. To analyze consumption perceptions, a cocktail was offered to consumers in order to understand if the classification given to the drink was higher when there was live music. The results of the live music condition expose positive effects on the taste of the drink. Moreover, consumers attribute a better quotation to the ambient and to the service of the bar in the live music condition than in ambient music condition. Otherwise, $61 \%$ of respondents fully agree with the statement "I can't live without music" when they were in live music condition against only $26 \%$ in ambient music condition. This may be explained by the fact that consumers are more sensitive to auditory stimuli when they are in the presence of live music.
\end{abstract}

References Available Upon Request

B. M. Ferreira $(\bowtie) \cdot D$. Marli

Polytechnic Institute of Viseu, Viseu, Portugal

e-mail: morgado.ferreira@estgv.ipv.pt; diana7marli@gmail.com

(C) Academy of Marketing Science 2019 